\title{
Chemical Analysis and Studies of Works of Art
}

DOI: $10.1134 / \mathrm{S} 1061934809030010$

There are a number of methods for revealing falsifications of paintings by well known artists, and prominent among them is the chemical analysis of pigments and even canvases on which paint is applied. Numerous examples are known when analytical studies of paints resulted in not only the confirmation or disconfirmation of the authenticity of the work of art, but also the correct dating of the painting, and the revelation of additions or restorations.

Let me present an example [1]. In 1994, a picture by the American artist William Walker (1839-1921) was on sale in the United States. One of the dealers doubted the authenticity of the work and through the FBI asked the professional analyst G. Martin (who also happens to be the founder of the Orion Analytical Company) to check the authenticity of the painting. Martin studied the layer of paint by IR spectroscopy. In this layer, he detected a yellow pigment that had come into use in the middle of the 1940s, which could not possibly have been used by Walker, who died in 1921. The picture was a fake. This was also confirmed by the results of the $X$-ray fluorescence study, which revealed white paint in this and other suspect paintings attributed to Walker, whereas it is known that the artist used white lead paint. FBI agents later found a gang specializing in producing
"Walker's paintings"; the head of the team was arrested and convicted.

Numerous examples of using x-ray spectroscopic methods of analysis in studying artworks were presented in the review [2]. The use of X-ray fluorescence analysis (XRF) in studying paintings is complicated by the multilayer character of the paint coating and the presence of the same elements, for example copper or iron, in many different pigments. Nonetheless, this method has helped researchers reach many important solutions regarding the study of paintings. X-ray analysis methods, including X-ray emission microanalysis and XRF, are widely used for assessing the authenticity of works; dating them; and in determining the place of manufacture of glass, ceramics, or metal and alloy artworks.

\section{REFERENCES}

1. Ember, L.R., Chem. Eng. News, 2007, vol. 85, no. 37, p. 28.

2. Revenko, A.G. and Revenko, V.A., Metody $i$ ob"ekty khim. anal., 2007, vol. 2, no. 1, p. 4.

Yu. A. Zolotov 